\title{
Leaching of a Gold Bearing Partially Roasted Sulphide.
}

\section{Laboratory Scale Studies}

\author{
M.F. Almeida* \\ Faculdade de Engenharia da Universidade do Porto, Rua Dr. Roberto Frias s/n, \\ 4200-465 Porto, Portugal
}

Received: June 19, 2001; Revised: October 12, 2001

\begin{abstract}
This research aimed at defining a route for recovering precious metals from a very heterogeneous gold bearing sulphide and arsenide concentrate that was partially roasted and dumped by the 1960s when Santo António mine closed. Gold occurs in this concentrate as free particles in the range of $10-100 \mu \mathrm{m}$, most of them still enclosed in the pyrite and arsenopyrite matrix. Its content varies from 20 to $150 \mathrm{~g}$ of $\mathrm{Au} / \mathrm{ton}$, being higher at the dump upper levels and in the finer concentrate fractions.

Preliminary tests demonstrated the refractoriness of this product, since the leaching with conventional cyanide solutions and with other leaching solutions gave very low recoveries. However, high concentrated cyanide solutions recover more than $60 \%$ of $\mathrm{Au}$, although with high $\mathrm{NaCN}$ and lime consumptions and poor settling characteristics. Iron was shown to be highly dissolved in these solutions.

Some prior treatments clearly favoured the cyanidation process, in particular a roasting step. Thus, a large number of roasting experiments was carried out to define the most favourable conditions for recovering gold. However, no clear relationship between roasting conditions and gold dissolution was found due to the heterogeneity of the product and high variance of gold experimental recoveries. These recoveries were calculated considering gold contained in both the leaching residues and leachates, and uncertainties of these results are relatively high.

Roasting the product at $450-700{ }^{\circ} \mathrm{C}$ for $1 \mathrm{~h}$ guarantees a high probability to dissolve at least $74 \%$ $\mathrm{Au}$ in a highly concentrated $\mathrm{NaCN}$ solution stirred for $24 \mathrm{~h}$. The $600-700^{\circ} \mathrm{C}$ roasting range is clearly preferable for consuming less cyanide and lime. Pre-washing the roasted product seems not to reduce the cyanide consumption.

Regarding the silver recovery, the $\mathrm{NaCN}$ and lime consumption are higher while using the products roasted at the lowest tested temperatures. Products roasted at higher temperatures have better settling performance.
\end{abstract}

Keywords: precious metals, cyanide, thiourea, roasting, recovery estimation

\section{Introduction}

Santo António gold mines are situated in the North of Portugal and were already explored in the 1st century A.D. by the Romans. These mines were reactivated around 1950 and closed 10 years later. The following two reasons explain to some extent such unsuccess: (i) an optimistic estimate of higher gold content was made; (ii) the flowsheet including a roasting step was based in few experimental tests. Thus, some unexpected surprises in the operation performance arose, namely low gold recoveries by cyanidation and poor gold cementation using Merril-Crowe process, with no de-aeration. Around 1980, two other soli-

*e-mail:mfa@fe.up.pt tary unsuccessful trials took place without continuity, perhaps due to the same intrinsic main causes, i.e., high refractoriness of the ore and very random gold content. One of those trials processed all the stocked ore by milling it up to a very fine grain size followed by cyanidation, adsorption of gold onto activated carbon, burning it and melting the resulting ashes ${ }^{1}$. The other is the core of this work carried out between 1984-1986, that aimed at recovering the gold content in a 2000 ton dump of partially roasted sulphide concentrate by adopting a batch operation in a small ownbuilt plant ${ }^{2}$. 
Cyanide is still the most used reagent for recovering gold from its ores. In the case of refractory ores containing complex minerals, gold dissolution is not a simple process and its rate becomes depressed after a certain time of cyanidation ${ }^{3}$. Mineralogical identification of the ore and diagnostic leaching are alternative methods for establishing and designing a metallurgical flowsheet for refractory ores $^{4}$. Some alternative leaching agents, namely thiourea, have been tried due to the environmental concerns, generally without economic success 5 . An usual approach for processing complex refractory gold ores is a pre-oxidation treatment prior the gold leaching step and the most known options are roasting, pressure oxidation and bioxidation ${ }^{6-8}$. Pressure oxidation is a technology where sulfuric acid can play an important role for oxidising arsenopyrite effectively $^{9-11}$. Biological processes are a reality as production technologies chosen for a significant refractory gold treatment plants worldwide. Several references discuss its application as biorector and bioheap leaching methods for refractory gold bearing sulphides and arsenides, where cyanide, as well as ammonium thiosulfate, are used as leaching agents ${ }^{12-17}$.

With the objective of designing a feasible flowsheet for recovering gold from those 2000 ton dump of partially roasted sulphide concentrate, following its mineralogical and chemical characterisation, some trials to concentrate gold by using magnetic separation and froth flotation processes were carried out without success. Then, several leaching screening tests were carried out using conventional cyanide concentrations of $0.5 \% \mathrm{w} / \mathrm{v} \mathrm{NaCN}$, conditioning the pulp and testing some treatments prior to cyanidation. Thiourea was tested as leaching agent, too. As general conclusion one can point out the failure of all those foreseen routes, except either leaching the concentrate with higher cyanide concentration or roasting it followed by cyanidation. Therefore, much more effort was invested in these two last lines of research.

\section{Gold Recovery Estimation}

Gold recovery is usually computed by using the following expression:

$$
\eta=\frac{m_{s} A u_{s}}{m_{s} A u_{s}+m_{r} A u_{r}}
$$

where $\mathrm{m}_{\mathrm{s}}$ is mass of solution, $\mathrm{m}_{\mathrm{r}}$ of residue and $\mathrm{Au}_{\mathrm{s}}$ and $\mathrm{Au}_{\mathrm{r}}$ are the gold contents $(\mathrm{w} / \mathrm{w})$ in solution and residue, respectively. The results obtained are expressed in percentage. However, if the gold bearing product is sufficiently uniform and the gold particles are very fine, a small variance in gold ore content is expected and gold recovery can be very well estimated by using the following expression:

$$
\eta=\frac{m_{\mathrm{s}} A u_{\mathrm{s}}}{\mathrm{m}_{\mathrm{p}} A u_{\mathrm{p}}}
$$

where $\mathrm{p}$ stands for product. It means that the ratio between the gold determined in the leachate and average gold content in the ore well estimates gold recovery and there is no need to determine gold in residues.

However, in the case of gold ores, the use of expression (1) is frequently a must. In this case, the estimate of recovery variance as a function of the different factors present in expression (1) is given by:

$$
\begin{aligned}
s_{\eta}^{2}=\left(\frac{\partial \eta}{\partial m_{s}}\right)_{0}^{2} s^{2}\left(m_{s}\right)+\left(\frac{\partial \eta}{\partial A u_{s}}\right)_{0}^{2} s^{2}\left(A u_{s}\right)+ \\
\left(\frac{\partial \eta}{\partial m_{r}}\right)_{0}^{2} s^{2}\left(m_{r}\right)+\left(\frac{\partial \eta}{\partial A u_{r}}\right)_{0}^{2} s^{2}\left(A u_{r}\right)
\end{aligned}
$$

where ()$_{0}$ means the derivative to be computed at the mean value of the variables. The development of this equation gives:

$$
\begin{gathered}
s_{\eta}^{2}=\left(\frac{m_{r} A u_{r} A u_{s}}{A u_{t}^{2}}\right)^{2} s^{2}\left(m_{s}\right)+\left(\frac{m_{r} m_{s} A u_{r}}{A u_{t}^{2}}\right)^{2} s^{2}\left(A u_{s}\right)+ \\
\left(\frac{m_{s} A u_{r} A u_{s}}{A u_{t}^{2}}\right)^{2} s^{2}\left(m_{r}\right)+\left(\frac{m_{r} m_{s} A u_{s}}{A u_{t}^{2}}\right)^{2} s^{2}\left(A u_{r}\right)
\end{gathered}
$$

where $A u_{t}=m_{r} A u_{r}+m_{s} A u_{s}=m_{p} A u_{p}$.

If one considers $\mathrm{s}^{2}\left(\mathrm{~m}_{\mathrm{s}}\right) \approx \mathrm{s}^{2}\left(\mathrm{~m}_{\mathrm{r}}\right) \approx 0$, since they are variance estimates of volume and mass measurements, generally less than $( \pm 0.01 * \text { magnitude measured })^{2}$, expression (4) reduces to:

$$
s_{\eta}^{2}=\left(\frac{m_{r} m_{s} A u_{r}}{A u_{t}^{2}}\right)^{2} s^{2}\left(A u_{s}\right)+\left(\frac{m_{r} m_{s} A u_{s}}{A u_{t}^{2}}\right)^{2} s^{2}\left(A u_{r}\right)(5),
$$

showing dependency on the gold solution and residue contents. Assuming optimistic errors of $3 \%$ for gold determination in solution by atomic absorption spectrometry (A.A.S.) and $15 \%$ for the laboratory way of sampling the residue, sample digestion, consequent dilutions of solutions up to A.A.S. determination, and substituting accordingly, the expression (5) becomes:

$$
\begin{gathered}
s_{\eta}^{2}=\left(\frac{m_{r} m_{s} A u_{r}}{A u_{t}^{2}}\right)^{2}\left( \pm 0.03 A u_{s}\right)^{2}+ \\
\left(\frac{m_{r} m_{s} A u_{s}}{A u_{t}^{2}}\right)^{2}\left( \pm 0.15 A u_{r}\right)^{2}=\left(\frac{m_{r} m_{s} A u_{r} A u_{s}}{A u_{t}^{2}}\right)^{2}\left(0.03^{2}+0.15^{2}\right)
\end{gathered}
$$

With recoveries expressed as percentages these estimates shall be multiplied by 10000 , or the square root of them (i.e., its standard deviation, taken as the normal error) multiplied by 100 . The magnitude of the uncertainty about the recovery created by those influences is sensible and can 
be illustrated by considering the following data: $\mathrm{m}_{\mathrm{r}}=1 \mathrm{~kg}$; $\mathrm{m}_{\mathrm{s}}=2 \mathrm{~kg} ; \mathrm{Au}_{\mathrm{r}}=15 \mathrm{~g} / \mathrm{ton} ; \mathrm{Au}_{\mathrm{s}}=27.5 \mathrm{~g} /$ ton. Sample average recovery is about $78.6 \%$ and estimated standard deviation is around $25.8 \%$. If $\mathrm{Au}_{\mathrm{r}}=7 \mathrm{~g} /$ ton then the calculated value for recovery is $90 \%$ and the standard deviation is $13.8 \%$.

These results indicate that uncertainty about true recovery values is much more affected by gold residue uncertainty than gold solution uncertainty, and it decreases as both gold content in the product and its recovery increase.

Based in these considerations and (i) assuming normal distribution for the recovery variable; (ii) estimating recovery variance by the above expression; (iii) considering $\mathrm{t}$ Student statistic defined as:

$$
\mathrm{t}=\frac{\bar{\eta}-\mu_{\eta}}{\mathrm{s}_{\eta}^{-}}
$$

where $\mu_{\eta}$ is the true mean recovery and $s_{\eta}$ is the sample standard deviation of the mean recovery; and (iv) respective $\mathrm{t}$ value at $\mathrm{t}$-Student tables, then intervals can be built where the true recovery value is contained with a given degree of confidence, generally taken as $95 \%$.

\section{Experimental}

A sample of about $100 \mathrm{~kg}$ was taken from the dumped sulphides and considered as a representative sample. Due to the known randomness of gold in the product, all the leaching tests used either 0.5 or $1 \mathrm{~kg}$ of ore. Experimental recoveries were computed through gold and silver values in both the final leachate and corresponding leaching residue. For this purpose the final leaching residue was first sampled, then the sample digested with hot aqua regia solution, followed by water washing the residue and then analysing the gold content in that solution by atomic absorption spectrometry (A.A.S.). This method of analysis was also used to determine other metals in the leachates and other solutions. In the case of gold determinations the background correction was used.

Commercial reagents and tap water were used for all the experimental work. In the leaching tests the pulp was agitated in a $5 \mathrm{~L}$ glass beaker and experiments were controlled by sampling leachates at predetermined times. Electrode immersion in the stirred pulp was used for monitoring $\mathrm{pH}$, and readings were taken only after stable $\mathrm{pH}$ values were achieved. For the cyanidation tests, lime was used to raise the $\mathrm{pH}$ to an alkaline level, and at the end of each experiment, the residue was washed with constant volumes of a stock lime solution. Free cyanide was determined by titration with silver nitrate using potassium iodide as indicator.

Carbon and sulphur in solid products were determined using an oxygen combustion method followed by absorption of the resulting gases. Carbon was quantified by the percentage of $\mathrm{CO}_{2}$ absorbed in a sodium hydroxide solution and sulphur was titrated as sulphate.

In order to simulate the industrial scale conditions, sulphides were roasted by using a $40 \mathrm{~cm}$ diameter $\mathrm{x} 100 \mathrm{~cm}$ length rotary kiln where the feed was directly heated by an air-propane flame that was turned on-off according to a temperature control device.

\section{Results and Discussion}

\subsection{Characterisation}

Gold occurs in the original ore generally in arsenopyrite that is associated with iron sulphides, mainly pyrite and chalcopyrite. Galena and sphalerite are also usual minerals and native bismuth occurs sometimes as small inclusions in arsenopyrite ${ }^{2}$. In the partially roasted sulphides bearing ore, gold was observed by microscopy as particles whose size was in the 10 to $100 \mu \mathrm{m}$ range, either as completely free or still inserted in grains containing sulphur and arsenium. Most of these grains still contain a few altered core that is bounded by a very porous surface resulting from both the industrial roasting step performed in a rotary kiln directly heated by a fuel-air flame, according to the old mine reports, and weathering. Grains of wolframite and pecheblend were also observed at the microscope. The only gold particle semi-quantitative analysis carried out revealed $63.6 \% \mathrm{Au}$ and $36.3 \% \mathrm{Ag}^{2}$.

Table 1 shows the size distribution analysis of 8 samples. Most of the coarser particles retained in the sieves are, in fact, agglomerates of finer particles, perhaps produced at the roasting step by rolling and binding the concentrate particles of sulphides. According to a previous analysis, the overall chemical composition of the product is 65.0 and $72.4 \mathrm{~g} /$ ton $\mathrm{Ag}$ and $\mathrm{Au}$, respectively; and in percentage, $\mathrm{SiO}_{2}=17.50 ; \mathrm{Fe}=32.74 ; \mathrm{S}=8.10 ; \mathrm{As}=5.00 ; \mathrm{Cu}=0.10^{18}$.

Table 2 presents the results obtained by analysing 14 different size fractions from about $8 \mathrm{~kg}$ sample. Gold, silver and most of the usual non-ferrous metals increase in the finer fractions, mainly those smaller than $0.150 \mathrm{~mm}$. Considering both the gold content in the 14 fractions and the respective mass percentage, computed average gold content is around $65 \mathrm{~g} /$ ton, less than $72.4 \mathrm{~g} /$ ton Au referred before. Due to the large relative variation of the finer and gold richer percentage sizes, a considerable scatter of the gold content of the samples is expected. In addition, it was also verified that average gold values corresponding to the deeper levels of the dump were unfortunately around $20 \mathrm{~g} /$ ton.

Carbon in the product was $1.95 \%$, probably due to the deposited organic matter from the vegetation at the dump surroundings. Sulphur was found to be $3.70 \%$. 
Table 1. Product size distribution analysis.

\begin{tabular}{|c|c|c|c|c|c|c|}
\hline Size $(\mu \mathrm{m})$ & $\begin{array}{c}\bar{X}=\text { mean } \\
\text { oversize }(\%)\end{array}$ & $\begin{array}{c}\mathrm{s}=\text { standard } \\
\text { deviation }(\%)\end{array}$ & $100 \overline{\mathrm{X}} / \mathrm{s}$ & $\bar{X} \pm t_{95 \%} \mathrm{~s} \overline{\mathrm{X}}(\%)$ & $\begin{array}{c}\text { Cumulative } \\
\text { oversize }(\%)\end{array}$ & $\begin{array}{c}\text { Cumulative } \\
\text { undersize }(\%)\end{array}$ \\
\hline 2360 & 22.16 & 3.35 & 15.11 & $18.81-25.51$ & 22.16 & 100.00 \\
\hline 1700 & 7.60 & 0.44 & 5.79 & $7.16-8.04$ & 29.76 & 77.84 \\
\hline 1180 & 6.42 & 0.54 & 8.48 & $5.88-6.96$ & 36.18 & 70.24 \\
\hline 850 & 6.81 & 0.26 & 3.87 & $6.55-7.07$ & 42.99 & 63.82 \\
\hline 600 & 5.45 & 0.21 & 3.93 & $5.24-5.66$ & 48.44 & 57.01 \\
\hline 425 & 7.37 & 0.39 & 5.26 & $6.98-7.76$ & 55.81 & 51.56 \\
\hline 300 & 8.91 & 0.43 & 4.84 & $8.48-9.34$ & 64.72 & 44.19 \\
\hline 212 & 13.07 & 3.16 & 24.17 & $9.91-16.23$ & 77.79 & 35.28 \\
\hline 150 & 11.77 & 2.00 & 17.01 & $9.77-13.77$ & 89.56 & 22.21 \\
\hline 106 & 6.90 & 1.28 & 18.53 & $5.62-8.18$ & 96.46 & 10.44 \\
\hline 75 & 2.44 & 0.99 & 40.74 & $1.45-3.43$ & 98.90 & 3.54 \\
\hline 53 & 0.74 & 0.60 & 80.62 & $0.14-1.34$ & 99.64 & 1.10 \\
\hline 38 & 0.32 & 0.17 & 52.28 & $0.15-0.49$ & 99.96 & 0.36 \\
\hline$\underline{0}$ & 0.04 & 0.02 & 57.86 & $0.02-0.06$ & 100.00 & 0.04 \\
\hline
\end{tabular}

Table 2. Chemical composition of several product fractions.

\begin{tabular}{|c|c|c|c|c|c|c|c|}
\hline Oversize $(\mu \mathrm{m})$ & $\mathrm{Au}$ (g/ton) & $\mathrm{Ag}$ (g/ton) & $\mathrm{Cu}$ (g/ton) & $\mathrm{Bi}$ (g/ton) & $\mathrm{Zn}$ (g/ton) & $\mathrm{Pb}$ (g/ton) & $\mathrm{Fe}(\%)$ \\
\hline 2360 & 42.0 & 59.0 & 1161 & 238 & 1613 & 770 & 26.16 \\
\hline 1700 & 43.8 & 20.0 & 1009 & 238 & 1383 & 800 & 22.98 \\
\hline 1180 & 54.9 & 42.0 & 983 & 236 & 1335 & 809 & 25.73 \\
\hline 850 & 50.4 & 24.0 & 984 & 235 & 1392 & 821 & 23.76 \\
\hline 600 & 75.7 & 44.3 & 628 & 220 & 1002 & 830 & 24.07 \\
\hline 425 & 50.6 & 41.4 & 618 & 203 & 1328 & 746 & 25.77 \\
\hline 300 & 67.2 & 53.3 & 839 & 205 & 1210 & 675 & 22.36 \\
\hline 212 & 51.9 & 58.8 & 832 & 196 & 1351 & 640 & 24.24 \\
\hline 150 & 76.3 & 59.4 & 989 & 210 & 1494 & 718 & 26.98 \\
\hline 106 & 102.3 & 63.0 & 1083 & 230 & 1542 & 639 & 30.53 \\
\hline 75 & 169.1 & 77.3 & 1164 & 241 & 1474 & 754 & 30.95 \\
\hline 53 & 293.0 & 97.7 & 7468 & 244 & 1686 & 786 & 31.47 \\
\hline 38 & 497.8 & 138.8 & 8043 & 273 & 1628 & 876 & 30.53 \\
\hline 0 & 2058.7 & 947.1 & 5179 & 269 & 1938 & 1595 & 34.26 \\
\hline
\end{tabular}

The product is naturally acid, and the aqueous suspension ( solid/water $=1$ ) has a $\mathrm{pH}$ ranging from 2.8 to $2.9,9$ to $11 \mathrm{~g} / \mathrm{L} \mathrm{Fe}$ and around $0.2 \mathrm{~g} / \mathrm{L} \mathrm{Cu}$.

\subsection{Screening tests}

Only about $9.5 \%$ of the product remained insensible to a weak magnetic field whereas $6 \%$ was strongly magnetic. Chemical analysis of 7 different magnetic fractions revealed no remarkable differences in $\mathrm{Au}, \mathrm{Ag}, \mathrm{Cu}, \mathrm{Bi}, \mathrm{Zn}$ and $\mathrm{Pb}$ contents. Therefore, it was not possible to take advantage of this property to concentrate the product.
Froth flotation at $\mathrm{pH}$ range of 9 to 10 using $\mathrm{Na}_{2} \mathrm{CO}_{3}$, reagent $3477 \AA$ and Aerofloat $25 \AA$ gave the results presented in Table 3. As shown in that table, despite an evident concentration, the tailings were not poor enough to be rejected.

Figures 1 and 2 summarise the product behaviour under normal cyanide leaching solutions of $0.5 \% \mathrm{w} / \mathrm{v} \mathrm{NaCN}$. In the second case, shown in Fig. 2, the leaching conditions were essentially equal but the product was dry milled to $<0.3 \mathrm{~mm}$. At the times assigned A and B more sodium cyanide was added to the pulp, respectively 0.17 and $4.32 \mathrm{~g}$ 
Table 3. Results of product froth flotation tests.

\begin{tabular}{lcrrrrr}
\hline \multirow{2}{*}{ Type of product } & \multirow{2}{*}{$\begin{array}{c}\text { Relative } \\
(\%)\end{array}$} & \multicolumn{2}{c}{ Content (g/ton) } & & \multicolumn{2}{c}{ Recovery (\%) } \\
\cline { 3 - 4 } \cline { 6 - 7 } & \multicolumn{1}{c}{$\mathrm{Au}$} & $\mathrm{Ag}$ & & $\mathrm{Au}$ & $\mathrm{Ag}$ \\
\hline Concentrate & 26.4 & 136.3 & 81.7 & & 49.3 & 38.6 \\
Tailings & 73.6 & 50.3 & 46.5 & & 50.7 & 61.4 \\
Feed & 100.0 & 73.0 & 55.8 & & 100.0 & 100.0 \\
\hline
\end{tabular}

in the first experiment and 0.13 and $3.93 \mathrm{~g}$ in the second leaching test.

The main indications of these tests were the following:

- the lime needed to achieve adequate alkalinity is very high, and despite of that, the pulp $\mathrm{pH}$ decreases with time;

- the settling and filtering pulp behaviour is clearly poor;

- the dissolved iron is lower than in acidic solutions, as expected, but it increases with stirring time;

- the initially small amount of dissolved gold is progressively lost by the solution, thus the overall gold recovery is very low;

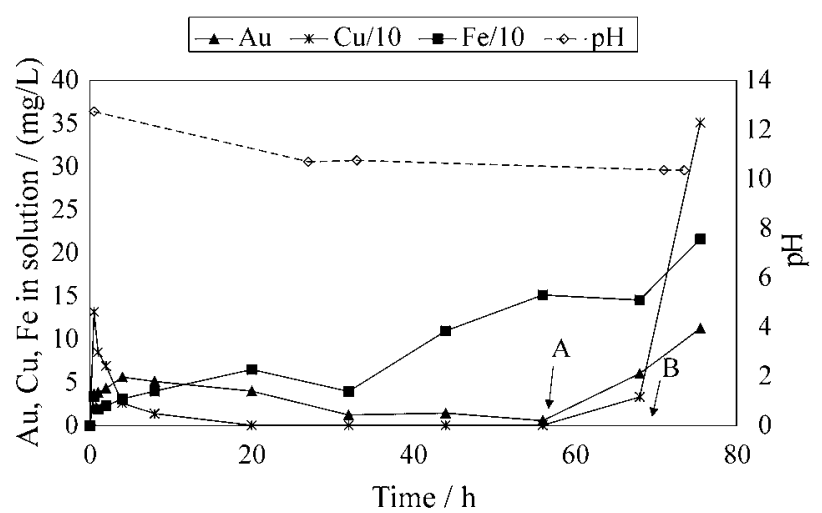

Figure 1. Product cyanidation using $0.5 \% \mathrm{NaCN}$ solution; $1 \mathrm{~kg}$ of product, $1 \mathrm{~L}$ of solution, $50 \mathrm{~g}$ of lime; 0.17 and $4.32 \mathrm{~g} \mathrm{NaCN}$ were added to the pulp at times A and B, respectively.

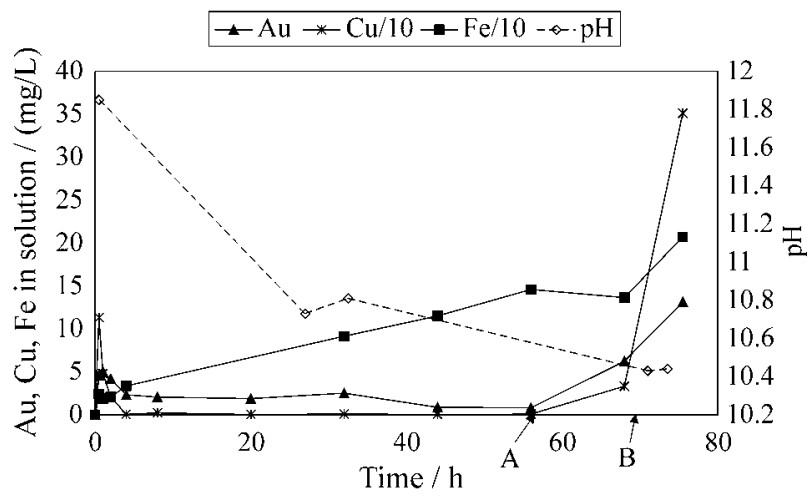

Figure 2. Cyanidation using $0.5 \% \mathrm{NaCN}$ solution and the product milled to $<0.3 \mathrm{~mm} ; 1 \mathrm{~kg}$ of product, $1 \mathrm{~L}$ of solution, $50 \mathrm{~g}$ of lime; 0.13 and $3.93 \mathrm{~g}$ $\mathrm{NaCN}$ were added to the pulp at times $\mathrm{A}$ and $\mathrm{B}$, respectively.
- further sodium cyanide additions to the stirred solutions immediately promote a visible increase in copper, gold and iron concentrations;

- size reduction does not affect substantially the product leaching behaviour.

It seems that cyanide degradation occurs in the bulk solution having gold losses as consequence. Thus, some alternatives to improve gold dissolution can be suggested: (a) the addition of much more cyanide, i.e., the use of higher concentrated cyanide solutions; (b) to submit the product to some specific treatments that either remove chemical species accounting for degrading cyanide or speeding up their transformation; and (c) use other leaching agents that can be expected to advantageously replace cyanide, such as thiourea.

\subsection{High concentrated cyanide solutions}

Figures 3 and 4 refer to two of those experiments carried out with high cyanide concentration. The general conclusion of these tests is that recoveries higher than $60 \%$ of $\mathrm{Au}$ are possible under the following leaching conditions: (i) adding 50-70 kg of lime per ton of product; (ii) stirring the pulp for $72 \mathrm{~h}$; (iii) maintaining not less than $0.2 \%$ of free cyanide in solution. However, high $\mathrm{NaCN}$ consumption, of around $70 \mathrm{~kg} / \mathrm{ton}$, is expected, and in order to avoid such $\mathrm{NaCN}$ consumption, the frequent monitoring of $\mathrm{pH}$ and free cyanide is recommended, since both decrease very fast at the first 15-20 $\mathrm{h}$ of leaching. Besides, maintaining high alkalinity, a good practice is having free cyanide concentration as low as possible so as to keep gold dissolving.

\subsection{Treatments prior to cyanidation}

Several treatments prior to cyanidation were tried, in general with no substantial success: dry milling all the product to $<0.3$ and $<0.1 \mathrm{~mm}$; prolonged pulp conditioning using lime; oxidising the pulp by an extended air bubbling; using lime rather than caustic soda for $\mathrm{pH}$ adjustment;

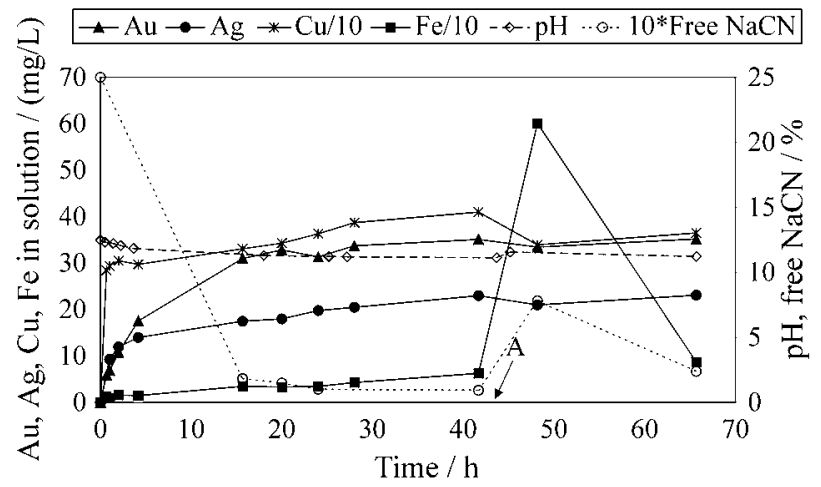

Figure 3. Product cyanidation using $2.5 \% \mathrm{NaCN}$ solution; $1 \mathrm{~kg}$ of product, $1 \mathrm{~L}$ of solution, $71 \mathrm{~g}$ of lime; $25 \mathrm{~g} \mathrm{NaCN}$ were added to the pulp at time A. Au recovery $=61.2 \%$. 


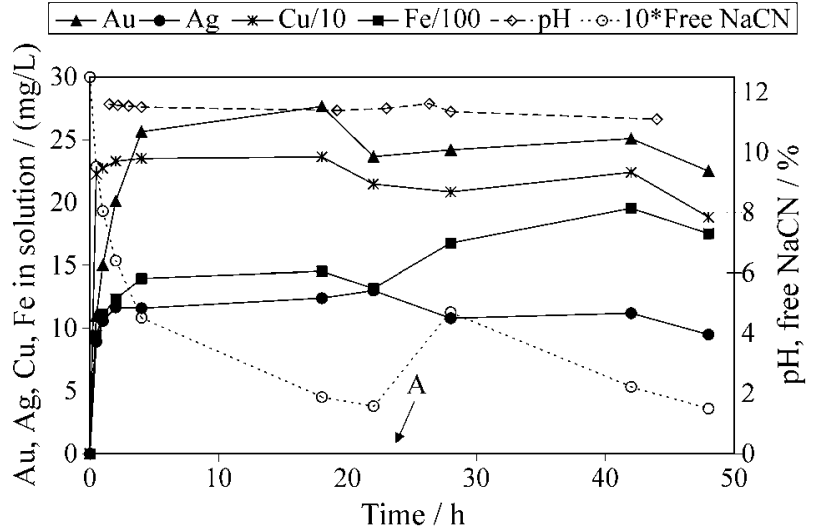

Figure 4. Product cyanidation using $1.25 \% \mathrm{NaCN}$ solution; $1 \mathrm{~kg}$ of product, $2 \mathrm{~L}$ of solution, $54 \mathrm{~g}$ of lime; $20 \mathrm{~g} \mathrm{NaCN}$ were added to the pulp at time A. Au recovery $=64.3 \%$.

pre-washing the product with water, $\mathrm{HCl}, \mathrm{HCl}+\mathrm{NH}_{4} \mathrm{Cl}$, $\mathrm{HNO}_{3}$ and $\mathrm{H}_{2} \mathrm{SO}_{4}$ solutions. These last two hot acid solutions improved cyanidation recoveries: $58 \%$ of the gold was recovered from the product previously hot washed with $\mathrm{HNO}_{3} 10 \%$ solution for $2 \mathrm{~h}$ at $65^{\circ} \mathrm{C}$; and, as shown in Fig. 5, about 56\% $\mathrm{Au}$ and $73 \% \mathrm{Ag}$ were recovered from the product previously hot washed with $7 \% \mathrm{v} / \mathrm{v}$ hot $\mathrm{H}_{2} \mathrm{SO}_{4}$ solution at $70-80{ }^{\circ} \mathrm{C}$. A sensible decrease in lime and $\mathrm{NaCN}$ consumption as well as in dissolved $\mathrm{Cu}$ and Fe relative to cyanidation with no acid washing treatment were also observed.

Figure 6 shows roasting as a very effective treatment prior to cyanidation, since $93 \%$ Au was recovered in the product heated to $700{ }^{\circ} \mathrm{C}$ for $1 \mathrm{~h}$. Moreover, a spectacular improvement in the settling and filtering capabilities of the pulp was achieved, as well as a reduced consumption of lime and $\mathrm{NaCN}$, and, in addition, much less iron was dissolved, too.

\subsection{Other leaching reagents}

Stirring the product for $24 \mathrm{~h}$ in a $20 \%$ dilute $\mathrm{HCl}+$ $\mathrm{HNO}_{3}$ 3:1 solution, under 1:3 solid:liquid ratio, around

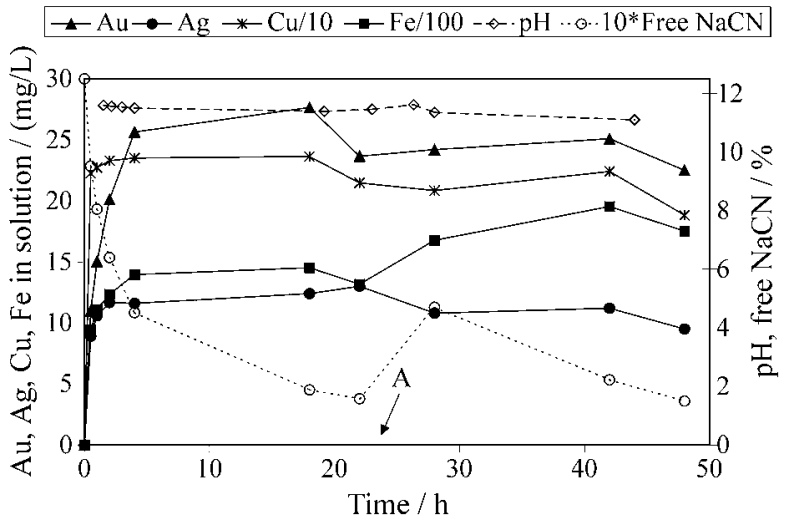

Figure 5. Product cyanidation using $0.67 \% \mathrm{NaCN}$ solution; $1 \mathrm{~kg}$ of product, $3 \mathrm{~L}$ of solution, $30 \mathrm{~g}$ of lime; $10 \mathrm{~g} \mathrm{NaCN}$ were added to the pulp at time $\mathrm{A}$. Au recovery $=55.7 \% ; \mathrm{Ag}$ recovery $=72.7 \%$.

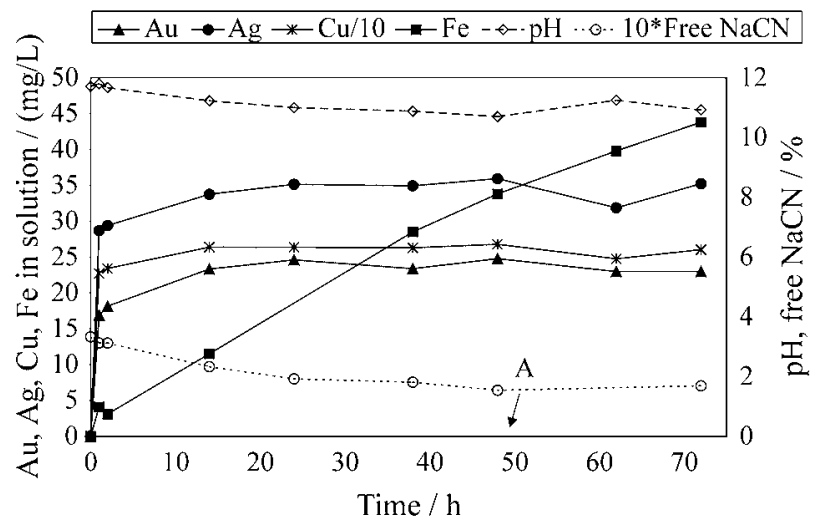

Figure 6. Product cyanidation using $0.5 \% \mathrm{NaCN}$ solution; $1 \mathrm{~kg}$ of product roasted at $700{ }^{\circ} \mathrm{C}, 2 \mathrm{~L}$ of solution, $18 \mathrm{~g}$ of lime; $400 \mathrm{~mL}$ of water and $2 \mathrm{~g}$ $\mathrm{NaCN}$ were added to the pulp at time A. Au recovery $=93.4 \%$.

$51 \%$ of $\mathrm{Au}$ was recovered. Further cyanidation of the residue contributed to add $15 \%$ to the already recovered gold, thus the overall Au recovery was $66 \%$.

By simultaneous stirring and electrolysing a pulp with a $10 \% \mathrm{NaCl}$ solution, thus producing chlorine, as a result of the oxidation of chloride ions, about $35 \%$ of Au was dissolved. Additionally, $28 \%$ of Au is recoverable in $24 \mathrm{~h}$ by cyanidation of the residue. This result confirms an already reported partial dissolution of gold using sodium hypochlorite solutions ${ }^{18}$.

Thiourea was not an effective leaching agent for this product. In fact, by using a thiourea leaching solution of $4 \% \mathrm{v} / \mathrm{v}$ at $\mathrm{pH}=1$, obtained by adding $\mathrm{H}_{2} \mathrm{SO}_{4}$, only $30 \%$ of the gold content was recovered and the resulting leachate contained more than $50 \mathrm{~g} / \mathrm{L}$ of iron. As in the cyanidation tests, the phenomena of loosing gold already dissolved was also observed during the thiourea leaching experiment. As shown in Fig. 7, even with the roasted product, thiourea leaching offers no remarkable advantage over cyanidation, since both gold and silver recoveries in such experiment

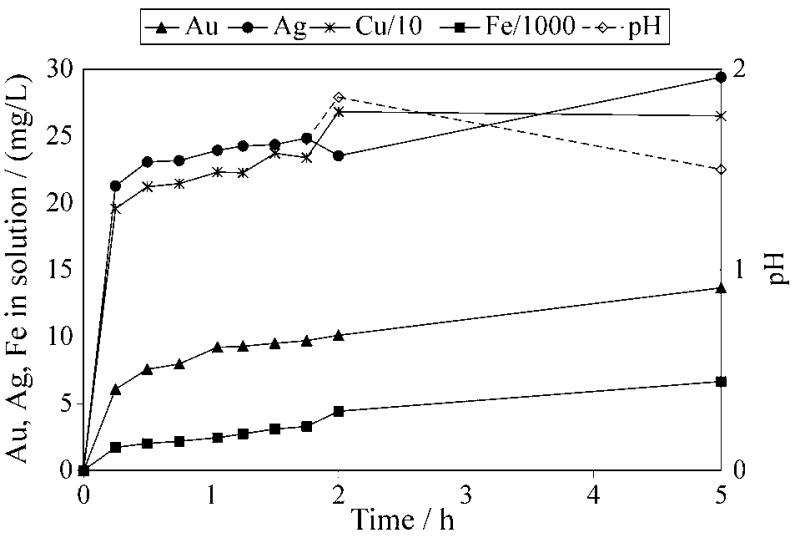

Figure 7. Product leaching using $2.67 \%$ thiourea solution; $1 \mathrm{~kg}$ of roasted product, $3 \mathrm{~L}$ of solution, $20 \mathrm{~mL} \mathrm{H}_{2} \mathrm{SO}_{4}$. Au recovery $=71.9 \%$; $\mathrm{Ag}$ recovery $=71.8 \%$. 
were about $72 \%$. Perhaps high thiourea concentration solutions and longer stirring times are needed.

\section{Development of a Cyanidation Route}

From the above results it is reasonable to assume that one of the cyanide consuming secondary reactions involves iron, perhaps through the following mechanisms:

$$
\mathrm{Fe}(\mathrm{OH})_{2}+6 \mathrm{CN}^{-} \rightarrow 2 \mathrm{OH}^{-}+\mathrm{Fe}(\mathrm{CN})_{6}^{4-}
$$

and

$$
\mathrm{FeS}+6 \mathrm{CN}^{-} \rightarrow \mathrm{Fe}(\mathrm{CN})_{6}^{4-}+\mathrm{S}^{2-}
$$

Iron hydroxide, $\mathrm{Fe}(\mathrm{OH})_{2}$, with $\mathrm{K}_{\mathrm{s}}=4.8 \times 10^{-16}$, probably forms, as a very fine precipitate, at the beginning of the experiments, after adding lime to the pulp. The high surface area of this precipitate turns reaction (8) quite possible to take place followed by the further oxidation of $\mathrm{Fe}(\mathrm{CN})_{6}{ }^{4-}$ to $\mathrm{Fe}(\mathrm{CN})_{6}{ }^{3-}$, whose $\mathrm{E}^{\mathrm{o}}=-0.358 \mathrm{~V}(\mathrm{SHE})$, thus increasing iron dissolution and cyanide consumption. Iron is also dissolved from sulphides minerals through reactions similar to (9) pushed by further oxidation of $\mathrm{S}^{2-} \rightarrow \mathrm{S}_{2} \mathrm{O}_{3}{ }^{2-}$ $\rightarrow \mathrm{SO}_{3}{ }^{2-} \rightarrow \mathrm{SO}_{4}{ }^{2-}$ and the low solubility of calcium sulphate formed by calcium from added lime. Moreover, the reaction between sulphate and cyanide ions produces thiocyanate ions, which contribute to increase cyanide consumption $^{19}$.

Anyway, either dissolving iron by acid pre-washing the product or increasing iron (III) and decreasing sulphur content by roasting it, both treatments reduce iron in leachates and decrease cyanide consumption.

Thus, in view of the preliminary results of gold recovery by the cyanidation of the roasted product, and due to the existence in the plant of two gas fired furnaces, one rotary kiln and one hearth furnace, it was decided to proceed by developing a metallurgical route involving roasting prior to cyanidation.

\subsection{Selection of roasting conditions}

The criteria adopted to select the conditions for roasting the product were the subsequent cyanidation gold and silver recoveries as well as sodium cyanide and lime consumption. Thus, some roasting tests were carried out at 450, 500, $550,600,650$ and $700{ }^{\circ} \mathrm{C}$ where the product was held for $1 \mathrm{~h}$. An additional two-step roasting cycle at $500{ }^{\circ} \mathrm{C}$ for $1 / 2 \mathrm{~h}$ and $625{ }^{\circ} \mathrm{C}$ for $1 / 2 \mathrm{~h}$ was carried out to generate maximum porosity in the pyrite and arsenopyrite mineral matrix $^{20}$.

Figure 8 shows that the sulphur content decrease as the temperature and roasting time increase. Arsenium was not analyzed but must be meaningful, since sometimes it was visible as white $\mathrm{As}_{2} \mathrm{O}_{3}$ even after finishing the roasting process. The product changed to a red bloody color for

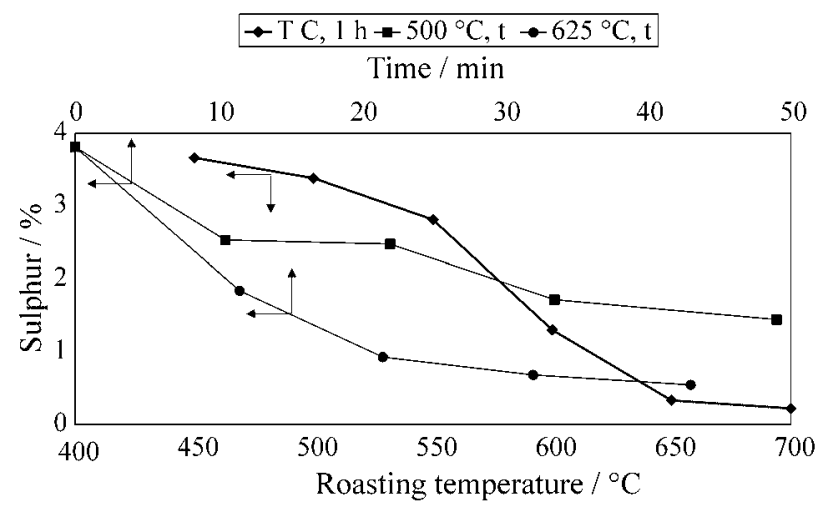

Figure 8. Sulphur in the products roasted under different conditions.

roasting temperatures higher than $600{ }^{\circ} \mathrm{C}$ due to $\mathrm{Fe}_{2} \mathrm{O}_{3}$ generation. For roasting temperatures $\geq 600^{\circ} \mathrm{C}$ the obtained products were much less acid than the original one. Consequently, much less lime is needed to obtain correct alkalinity for cyanidation; conversely, if the product was roasted at temperatures $\leq 550{ }^{\circ} \mathrm{C}$, the lime needed for achieving correct alkalinity is still high and approximately the one needed at the initial condition when the roasting process was carried out at $450{ }^{\circ} \mathrm{C}$. The pre-washing can reduce the lime consumption mainly at these lower roasting temperatures, according to the data shown in Table 4.

The roasted products were leached for $24 \mathrm{~h}$ in stirred triplicate tests with an initial addition of $50 \mathrm{~kg} \mathrm{NaCN} /$ ton of product and a 1:3 solid:liquid ratio. The perspective of using an excessively high cyanide concentration intended: (i) a correct basis of comparison with those preliminary cyanidation tests where original product was used; (ii) to guarantee an excess of reagent during the stirring time, to have a permanent dissolution capacity to all the leaching solutions.

Figure 9 shows the free cyanide concentration against time for some tests with no pre-washing but with pre-conditioning step, except the $500 / 625{ }^{\circ} \mathrm{C}$ case. Table 5 shows the cyanide consumption for some leaching tests. The

Table 4. Lime consumption with roasted products, $\mathrm{kg} / \mathrm{ton}$.

\begin{tabular}{lcc}
\hline $\begin{array}{l}\text { Roasting } \\
\text { temperature }\left({ }^{\circ} \mathrm{C}\right)\end{array}$ & No pre-washing & Pre-washing \\
\hline 450 & $60-65$ & $45-50$ \\
500 & $50-55$ & $25-30$ \\
550 & $46-51$ & $27-32$ \\
600 & $<10$ & n.d. \\
500,625 & $3-5$ & $2-4$ \\
650 & n.d. & $<4$ \\
700 & n.d. & $<2$ \\
\hline
\end{tabular}

n.d. - not determined. 


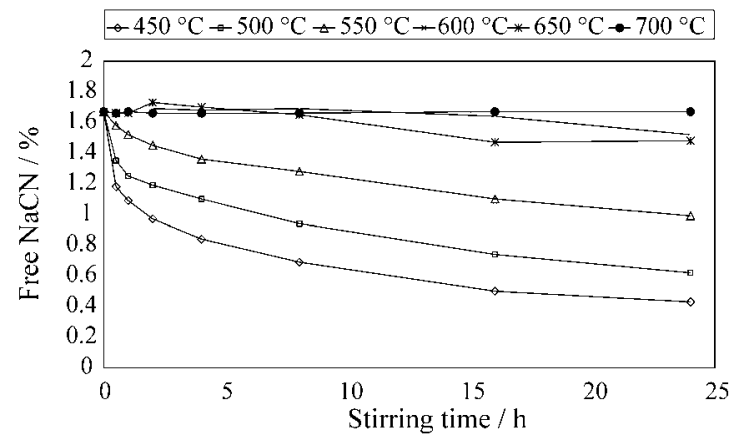

Figure 9. Free cyanide in the leaching tests using products roasted at different temperatures for $1 \mathrm{~h} ; 1.67 \% \mathrm{NaCN}$ initial concentration, $1: 3$ solid:liquid ratio.

Table 5. NaCN consumption in cyanidation of the roasted products.

\begin{tabular}{lcccc}
\hline $\begin{array}{l}\text { Roast. temper- } \\
\text { ature }{ }^{1)}\left({ }^{\circ} \mathrm{C}\right)\end{array}$ & $\begin{array}{c}\text { Pre-washi } \\
\text { ng }\end{array}$ & $\begin{array}{c}\text { Condi- } \\
\text { tioning }\end{array}$ & $\begin{array}{c}\mathrm{NaCN} \\
(\mathrm{kg} / \mathrm{ton})\end{array}$ & $\begin{array}{c}\mathrm{b}_{1} \text { value } \\
(\mathrm{x} \mathrm{10})\end{array}$ \\
\hline 450 & no & yes & 37.1 & -30.5 \\
450 & yes & yes & 37.2 & -41.4 \\
500 & no & yes & 31.3 & -23.2 \\
500 & yes & yes & 37.4 & -33.6 \\
550 & no & yes & 25.0 & -- \\
550 & no & yes & 20.4 & -13.9 \\
550 & yes & yes & 22.4 & -13.9 \\
600 & no & yes & 9.0 & -- \\
$500,625^{2)}$ & no & no & 15.4 & -10.3 \\
$500,625^{2)}$ & yes & no & 22.8 & -14.2 \\
650 & no & yes & 5.7 & -4.9 \\
650 & yes & yes & 11.4 & -6.9 \\
700 & no & yes & 0.1 & - \\
700 & yes & yes & 8.1 & - \\
\hline
\end{tabular}

Holding time: ${ }^{1)} 1 \mathrm{~h} ;{ }^{2)} 1 / 2 \mathrm{~h}$ at $500{ }^{\circ} \mathrm{C}, 1 / 2 \mathrm{~h}$ at $625^{\circ} \mathrm{C}$.

conclusions are the following: (i) $\mathrm{NaCN}$ needed to leach the roasted products is less than that to leach the non-roasted product; and, (ii) the $\mathrm{NaCN}$ consumption increases for products roasted at lower temperatures, and surprisingly, for products pre-washed. This anomalous fact was attributed to the very strongly contamination of the water used at the washing step that was collected from a well strongly contaminated by leachates from some tons of product.

A linear regression model as $\log ($ free $\mathrm{NaCN}, \%)=\mathrm{b}_{0}+$ $b_{1}$ (time, min) fitted to all the experiments, explains, reasonably, the free cyanide changes for most of the experiments carried out, mainly after the beginning of the leaching process. Therefore, this model could be used for
Table 6. $\mathrm{Au}$ and $\mathrm{Ag}$ average recoveries in roasted products cyanidation, $\%$.

\begin{tabular}{lcc}
\hline $\begin{array}{l}\text { Roasting } \\
\text { temperature }\left({ }^{\circ} \mathrm{C}\right)\end{array}$ & $\mathrm{Au}$ & $\mathrm{Ag}$ \\
\hline 450 & 79.8 & 73.2 \\
500 & 84.2 & 64.8 \\
550 & 81.2 & 57.8 \\
600 & 78.4 & 35.9 \\
500,625 & 77.5 & 35.0 \\
650 & 86.3 & 46.1 \\
700 & 79.4 & 42.3 \\
\hline
\end{tabular}

monitoring the free cyanide concentration with time. The fact that $\mathrm{NaCN}$ consumption increases inversely to the roasting temperature and with pre-washing is reflected by the time coefficient in the regression expression as it is presented in the last column of Table 5 for 10 average experiments.

Two statistical hypothesis tests using the differences between either the $\mathrm{Au}$ or $\mathrm{Ag}$ recovery values, from the cyanidation of the pre-washed and non-pre-washed roasted products, were done in order to assess meaningful different leaching behaviour. Despite the average $\mathrm{Au}$ and $\mathrm{Ag}$ recoveries in pre-washed products have mean differences of 2.07 and $7.75 \%$ respectively, higher than in the non-washed products, the hypothesis test based on the t-Student statistic gives no evidence to reject the null hypothesis of equal $\mathrm{Au}$ or $\mathrm{Ag}$ recoveries for both washed and non-washed products. In consequence, Table 6 shows the pooled Au and Ag average recoveries ranked by the roasting temperatures. Clearly, the highest Ag recoveries are related to the lowest roasting temperatures in the range and the highest Au recovery is found for the $650{ }^{\circ} \mathrm{C}$ product, although not very different from other values. However, those mean values do not reflect the large variability for both $\mathrm{Ag}$ and Au recoveries, a characteristic shown better in Figs. 10 and 11 where true mean $\mathrm{Au}$ and $\mathrm{Ag}$ recoveries 95\% confidence intervals were built for different experiments with the roasted products. The product roasted at $650{ }^{\circ} \mathrm{C}$ has the highest mean Au recovered value of $92.1 \%$. Similar gold recoveries even higher than $81 \%$ were obtained for the $500{ }^{\circ} \mathrm{C}$ product. Therefore, these values do not assign clearly the best roasting conditions for recovering gold in the ore; and looking at the recoveries frequency distribution, it can only be said that cyanidation has a probability of about $60 \%$ to recover at least $80 \%$ of gold (or around $93 \%$ to recover more than $74 \%$ of $\mathrm{Au}$ ) in the products roasted under any of the tested conditions. In consequence, other criteria, as silver recovery, cyanide and lime consumptions must decide among all the experiments. By 


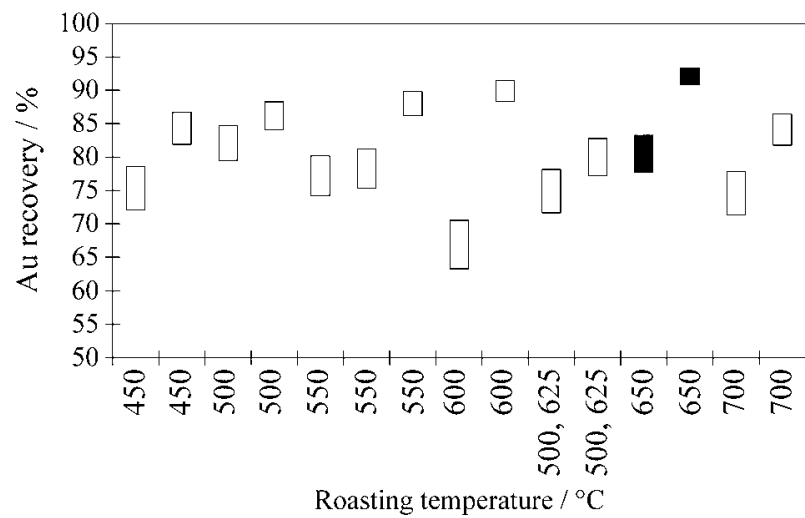

Figure 10. Mean gold recovery $95 \%$ confidence intervals from cyanidation tests with different roasted products.

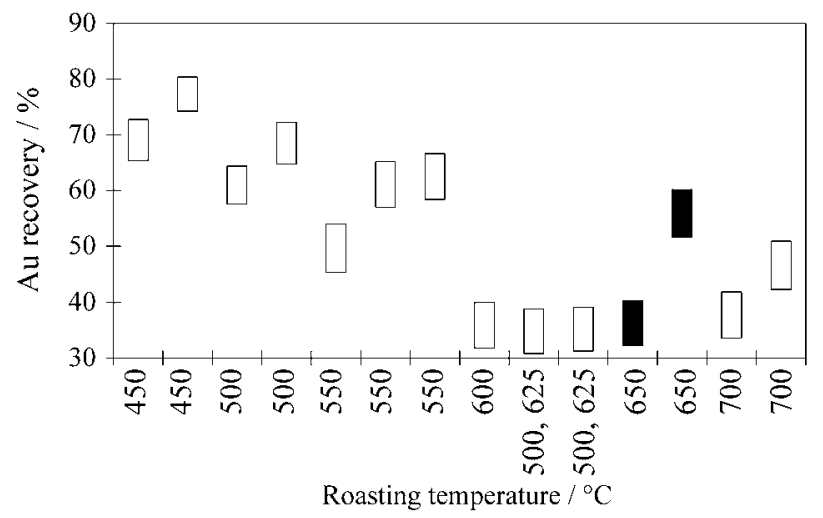

Figure 11. Mean silver recovery $95 \%$ confidence intervals from cyanidation tests with different roasted products.

weighing the value of silver recovered and $\mathrm{NaCN}$ and lime costs, roasting temperatures in the range of 600 to $700{ }^{\circ} \mathrm{C}$ seem to be preferable. Additionally, the resulting residues settle and filter better.

Despite the evident possibility of increasing precious metals recoveries, by increasing stirring time, the overall results are not that high. In fact, gold and silver in the roasted products were in the range of 35.2 to $153.4 \mathrm{~g}$ of $\mathrm{Au} /$ ton of product, with a $78.1 \mathrm{~g} / \mathrm{ton}$ mean average, and 25.4 to $69.3 \mathrm{~g}$ of $\mathrm{Ag} / \mathrm{ton}$ of product, with a $45.4 \mathrm{~g} / \mathrm{ton}$ mean average. However, the respective leaching residues were in the range of 4.1 to $36.5 \mathrm{~g}$ of Au/ton of residue, with a $11.0 \mathrm{~g} / \mathrm{ton}$ mean average, and 10.2 to $38.4 \mathrm{~g}$ of Ag/ton of residue with a $21.6 \mathrm{~g} / \mathrm{ton}$ mean average. That is, residues are not still a worthless raw material.

\section{Conclusions}

In this gold sulphide concentrate three main reasons explain most of the variability response found at leaching tests: (i) gold exists as free and non-free particles with sizes of $<10 \mu \mathrm{m}$ to $>100 \mu \mathrm{m}$; (ii) the product has completely roasted particles, as well as partially and almost intact sulphides particles; and (ii) the granulometric composition of the samples is quite different and gold in finer fractions is higher than in coarse ones. As consequence, the samples of sulphide concentrate used in the tests showed a sensible gold content scattering.

Even using either 0.5 or $1 \mathrm{~kg}$ samples of sulphide concentrate, in the experiments carried out, and computing gold recoveries considering the gold content in both the corresponding solutions and residues, significant differences in gold recoveries were still found under similar leaching conditions.

The cyanidation of this product, using conventional $\mathrm{NaCN}$ concentration of $0.5 \% \mathrm{w} / \mathrm{v}$, was not feasible, since the small amount of gold initially dissolved, was easily lost, and final gold recovery was very low. Some of the added cyanide was spent reacting with copper and iron, but other secondary reactions that consume cyanide may occur, such as those producing thiocyanate ions. Additionally, very high lime amount, of about 50 to $70 \mathrm{~kg} / \mathrm{ton}$ of product, was needed for adjusting pulp alkalinity, and the solutions obtained, settle and filter poorly.

Thiourea showed to be a non-effective reagent to recover the gold contained in this partially roasted sulphide material and offered no visible advantages over cyanide, a less expensive leaching reagent.

By using highly concentrated cyanide solutions, about $60 \%$ of $\mathrm{Au}$ in the concentrate was leached with no prior treatments. However, both poor settling and filtering characteristics remained. With these solutions long stirring time of about $72 \mathrm{~h}$ is recommended and high cyanide consumption of around $70 \mathrm{~kg}$ of $\mathrm{NaCN} /$ ton of product must be expected. Carefully monitoring the leaching process in order to maintain free cyanide around $0.2 \%$, as $\mathrm{NaCN}$, can reduce substantially the amount of such reagent used during the leaching process.

As expected, milling the partially roasted sulphide did not benefit gold recovery, due to the non-significant relative increase of surface exposed to cyanidation in this already porous and weathered product.

Among prior treatments, $\mathrm{HNO}_{3}$ and $\mathrm{H}_{2} \mathrm{SO}_{4}$ acid prewashing were effective for improving settling capability, for reducing iron and copper dissolution and affording $\mathrm{NaCN}$.

The roasting process has made substantial modifications in the product: (i) improved settling behavior; (ii) less iron was dissolved; (iii) lime and $\mathrm{NaCN}$ consumption were reduced; and (iv) more gold was dissolved in less stirring times.

The effect of roasting conditions on this heterogeneous product, as evaluated by the cyanidation experiments carried out, was the following: (i) silver recoveries are higher for the lowest roasting temperatures at the $450-700{ }^{\circ} \mathrm{C}$ range; (ii) lime and $\mathrm{NaCN}$ consumption are lower for 
products roasted at the upper temperatures in that range; (iii) pre-washing the roasted products reduces lime required for adjusting $\mathrm{pH}$ of the pulp, mainly for those roasted at $550{ }^{\circ} \mathrm{C}$ or below; (iv) after roasting the product for $1 \mathrm{~h}$ at any temperature, in the $450-700{ }^{\circ} \mathrm{C}$ range, one can say that there is a probability of about $93 \%$ that highly concentrated cyanide solutions leach at least $74 \%$ of the $\mathrm{Au}$, in $24 \mathrm{~h}$; (v) there is no evidence for believing that pre-washing the roasted products improves either gold or silver recoveries.

\section{Acknowledgements}

The author wish to thank the already unexistent Portuguese branch of Compagnie Asturienne des Mines, through its manager Ing. Cavalheiro, for providing the conditions to carry out this work.

\section{References}

1. Espiell, F. et al., Obtención de oro y plata por cianuración directa de menas arsenopiríticas de la zona de Penedono (Portugal). Experimentación en planta piloto, Rev. Metal. Madrid, v. 22, p. 4, 1986.

2. Almeida, M.F. Hidrometalurgia dos Minérios Auríferos, Ph.D. thesis. FEUP, Porto, 1987.

3. Lorenzen, L.; Van Deventer, J.S.J. Mechanism of leaching of gold from refractory ores, Minerals Engineering'92, n. 5, p. 1377, 1992.

4. Lorenzen, L.; Van Deventer, J.S.J. Mineralogical identification of refractory gold ores by means of the selective decomposition of minerals, Proceedings of the International Conference on Extractive Metallurgy of Gold and Base Metals, p. 171, 1992.

5.Zhang, Y.Z. Evaluation of thiourea consumption for gold extraction from complex and refractory gold ores, Proceedings of the 1996 125th TMS Annual Meeting, p. 443, 1996.

6. Brittan, M. Oxygen roasting of refractory gold ores, Mining Engineering, n. 47, p. 145, 1995.

7. Lingue, H.G. New technology for refractory gold ores, Proceedings of the International Conference on Extractive Metallurgy of Gold and Base Metals, p. 339, 1992.

8. Slater, C. et al., Comparative analysis of U.S. environmental control technologies for refractory gold pre- treatment processes, Industry and Environment, n. 18, p. 93, 1995.

9. Gathje, J. et al., Pressure-oxidation process development: beware of lab results, Mining Engineering, n. 47, p. 520, 1995.

10. Long, H.; Dixon, D. Kinetic study of pressure oxidation of pyrite at high temperatures, Proceedings of TMS Annual Meeting 1999, p. 457, 1999.

11. Li, D. et al., Studies of a non-toxic process to extract gold from refractory ores by the pretreatment of sulfuric acid oxidation, Journal of Xiangtan Mining Institute, n. 14, p. 39, 1999.

12. Natarajan, K.A. Biological processing of refractory gold ores, Journal of Mines, Metals \& Fuels, n. 42, p. 325, 1994.

13. Brierley, C. Bacterial oxidation, Engineering and Mining Journal, n. 196, p. 42, 1995.

14. Lynn, N. Bioleaching and processing of a refractory gold ore, Global Exploitation of Heap Leachable Gold Deposits TMS Annual Meeting 1997, p. 83, 1997.

15. Shutey-McCann, M.L. et al., Operation of Newmonts bioxidation demonstration facility, Global Exploitation of Heap Leachable Gold Deposits TMS Annual Meeting 1997, p. 75, 1997.

16. Wan, R.Y.; Brierley, J.A. Thiosulfate leaching following bioxidation pretreatment for gold recovery from refractory carbonaceous-sulfidic ore, Mining Engineering, n. 49, p. 76, 1997.

17. Deng, T.L. et al., Investigations of accelerating parameters for the bioxidation of low-grade refractory gold ores, Minerals Engineering, n.13, p.1543, 2000.

18. Ricouart P. Extraction d'or present dans un tailing provenant du Portugal, report, Service de Recherches Métallurgiques, Asturienne France, 1985.

19. Fleming C.A. A process for the simultaneous recovery of gold and uranium from south african ores, Gold 100, Proceedings of the International Conference on Gold, , n. 2, p. 301, SAIMM, Johannesburg, 1986.

20. Arriagada, F.; Osseo-Asare, K. Gold extraction from refractory ores: roasting behaviour of pyrite and arsenopyrite, Proceedings of Precious Metals: Mining, Extraction and Processing, International Symposium on Precious Metals, p. 367, 1984. 